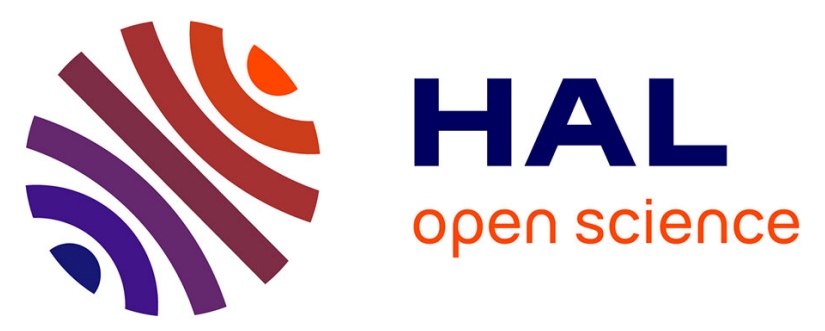

\title{
APPLICATION OF 3-HYDROXYBUTYRATE MEASUREMENT AND PLASMA PROTEIN ELECTROPHORESIS IN THE DIAGNOSIS OF ASPERGILLOSIS IN AFRICAN PENGUINS (SPHENISCUS DEMERSUS)
}

Guillaume Desoubeaux, Marilyn Rodriguez, Ellen Bronson, Gayle Sirpenski, Carolyn Cray

\section{- To cite this version:}

Guillaume Desoubeaux, Marilyn Rodriguez, Ellen Bronson, Gayle Sirpenski, Carolyn Cray. APPLICATION OF 3-HYDROXYBUTYRATE MEASUREMENT AND PLASMA PROTEIN ELECTROPHORESIS IN THE DIAGNOSIS OF ASPERGILLOSIS IN AFRICAN PENGUINS (SPHENISCUS DEMERSUS). Journal of Zoo and Wildlife Medicine, 2018, 49 (3), pp.696-703. 10.1638/20170172.1. hal-02439676

\author{
HAL Id: hal-02439676 \\ https://hal.science/hal-02439676
}

Submitted on 17 Jan 2020

HAL is a multi-disciplinary open access archive for the deposit and dissemination of scientific research documents, whether they are published or not. The documents may come from teaching and research institutions in France or abroad, or from public or private research centers.
L'archive ouverte pluridisciplinaire HAL, est destinée au dépôt et à la diffusion de documents scientifiques de niveau recherche, publiés ou non, émanant des établissements d'enseignement et de recherche français ou étrangers, des laboratoires publics ou privés. 
RH: HYDROXYBUTYRATE IN PENGUIN ASPERGILLOSIS

\section{APPLICATION OF 3-HYDROXYBUTYRATE MEASUREMENT AND PLASMA PROTEIN ELECTROPHORESIS IN THE DIAGNOSIS OF ASPERGILLOSIS IN 5 AFRICAN PENGUINS (SPHENISCUS DEMERSUS)}

Guillaume Desoubeaux Pharm.D. Ph.D., Marilyn Rodriguez B.S. M.T., Ellen Bronson D.V.M., Dipl. A.C.Z.M., Gayle Sirpenski B.S., and Carolyn Cray Ph.D*

From the University of Miami, Division of Comparative Pathology, Department of Pathology \& Laboratory Medicine, Miller School of Medicine, Miami, FL 33136 - U.S.A. (Desoubeaux, Rodriguez, Cray); CHU de Tours, Service de Parasitologie - Mycologie - Médecine tropicale, Tours - France (Desoubeaux); Université François-Rabelais, CEPR - INSERM U1100 / Équipe 3, Faculté de Médecine, 37000 Tours - France (Desoubeaux); Maryland Zoo in Baltimore, 15 Baltimore, MD 21217 - U.S.A. (Bronson); Mystic Aquarium, Mystic, CT 06355 - U.S.A. (Sirpenski)

* Corresponding author: ccray@ med.miami.edu

Current address: Division of Comparative Pathology, Department of Pathology \& Laboratory 20 Medicine

University of Miami, Miller School of Medicine, Miami, FL 33136- U.S.A.

Phone: $+1(305) 243-6700$

Fax: +1(305) 243 - 5662 
Abstract: New alternative laboratory means are needed to improve the options for antemortem diagnosis of avian aspergillosis. In this study, 3-hydroxybutyrate was measured in plasma samples collected from a cohort of African penguins (Spheniscus demersus) maintained under human care. Results were interpreted in combination with those of protein electrophoresis and compared to anti-Aspergillus antibody and galactomannan antigen

30 detection. Overall, 3-hydroxybutyrate levels were found significantly increased in Aspergillusdiseased cases versus control penguin groups $(P=0.002)$. Mean absolute concentration of $\beta$ globulins was increased $>20 \%$ in samples from infected birds, and $\alpha 2$-globublins were also found to be significantly increased $v s$. control groups $(P=0.001)$. Consequently, the combination of increased 3-hydroxybutyrate and increased $\alpha 2$-globulins did have a higher 35 specificity than both markers alone $(98.4 \% v s .78 .6 \%$ and $92.2 \%$, respectively; $P<0.05)$. Elevated 3-hydroxybutyrate levels combined with increases in $\alpha 2$-globulins or with any electrophoresis abnormalities reflected a high negative predictive value of $79.9 \%$ or $86.7 \%$, respectively, vs. $64.7 \%$ when 3 -hydroxybutyrate was considered alone $(P<0.05)$. In contrast, anti-Aspergillus antibody and galactomannan antigen did not distinguish between infected cases and controls $(P>0.05)$. This study demonstrates that basic testing in tandem with the new biomarker 3-hydroxybutyrate may provide reliable evidence for the diagnosis of aspergillosis in penguins.

Key words: Aspergillus, aspergillosis, electrophoresis, penguin, hydroxybutyrate, diagnostic assay. 


\section{INTRODUCTION}

Aspergillosis is a fungal airborne infection caused by ubiquitous molds of the Aspergillus genus. Aspergillosis can lead to fatal outcome both in diseased humans and animals, especially when the diagnosis is delayed and the antifungal therapy is inadequate. ${ }^{19,23}$ Some birds are known to be particularly susceptible to aspergillosis, including African penguins (Spheniscus demersus) which are maintained under human care in aquaria or during rehabilitation. ${ }^{9}$ Unfortunately, avian aspergillosis remains difficult to diagnose as current laboratory diagnostics do not have consistent high sensitivity and specificity. In penguins, samples are

55 often found negative for galactomannan antigen detection, ${ }^{8}$ while most have high levels of antiAspergillus antibody reactivity regardless of clinical status. ${ }^{7}$ Biopsy sampling for fungal culture or histopathology can be difficult to perform in ill or debilitated patients. Furthermore, some medical imaging, e.g. celioscopy, is also not readily available in every facility, while radiography is often unreliable and rarely yields findings for aspergillosis in penguins. ${ }^{7}$

60 Veterinary practitioners currently depend on plasma protein electrophoresis $(\mathrm{EPH})$ to address the diagnosis of aspergillosis and initiate preemptive antifungal treatment. ${ }^{3,8}$ Quantitation of serum proteins has been shown to provide a reflection of acute phase responses through the demonstration of change in albumin, a negative acute phase protein, and four globulin fractions which are often increased with different disease processes. ${ }^{12}$ The diagnostic and prognostic application of data obtained from commercial semi-automated methods of protein fractionation has been well described in veterinary medicine. ${ }^{12,17}$ Thus, plasma electrophoresis has become more widely utilized in avian medicine over the last 20 years. ${ }^{2,4,5,20,25}$

Proteomics and metabolomics are innovative tools that enable the ex vivo study of pathologic processes. Their use in research has previously defined possible new biomarkers of

70 infection. ${ }^{10,11}$ Recently, a significant increase of some lipoproteins, fatty acids and ketone bodies including 3-hydroxybutyrate, ${ }^{24}$ was highlighted in falcons with Aspergillus fumigatus 
versus healthy birds, ${ }^{21}$ through proton nuclear magnetic resonance spectroscopy and robust multivariate analysis. Elevation of 3-hydroxybutyrate is believed to indicate behavioral and/or metabolic adjustments directed to spare energy and body protein during infection. ${ }^{8}$ It indirectly reflects the need for activating fat mobilization. ${ }^{1}$ In experimental studies, it was demonstrated to increase in some vertebrate species especially in birds, ${ }^{1,22}$ but comprehensive clinical trials are lacking. In the present study, the diagnostic value of 3-hydroxybutyrate measurement in a cohort of blood samples from African penguins that were undergoing aspergillosis was assessed with comparison and in combination with $\mathrm{EPH}$.

\section{MATERIALS AND METHODS}

Case definition. The definitive diagnosis of "proven" or "probable" fungal infection had been assigned according to the classification derived from the definition utilized in human medicine. ${ }^{9}$ "Proven" cases were based on histopathologic evidence $(n=7)$ and "probable" cases had positive fungal cultures in conjunction with clinical signalment and corroborative imaging investigations $(n=15)$. Penguins with clinical signs of aspergillosis, but with neither positive fungal cultures / histopathology evidences nor imaging findings available, were considered "possible" diagnosis $(n=25)$., if they responded to antifungal treatment. ${ }^{7}$ The control groups included penguins undergoing varied non-Aspergillus inflammatory diseases and clinicallynormal birds.

The ages of the clinical groups were as follows: Aspergillus-diseased, 8.5 +/- 3.9 years; inflammatory controls, $23.8+/-4.0$ years; clinically normal controls, $8.4+/-3.8$ years. The percentages of male patients in each group were $69.6 \%, 56.3 \%$, and 51.6\%, respectively.

Diagnostic testing. Blood samples were drawn from penguin flipper vein, then heparinized in

95 lithium tubes and centrifuged. If free from hemolysis and lipemia, ${ }^{3-6}$ plasma specimens were 
refrigerated until analysis within 24 hours of submission to the laboratory. ${ }^{10}$ Otherwise, they were frozen at $-80^{\circ} \mathrm{C}$.

Detection of anti-Aspergillus antibody was conducted via a previously described ELISA technique using bulk Aspergillus ID antigens made of pooled mycelial-phase culture filtrates of 100 Aspergillus species (IMMY, Norman, OK, 73071, U.S.A.). ${ }^{7}$ Galactomannan antigen was measured in blood according to the manufacturers' recommendations (Bio-Rad Clinical Diagnostics, Hercules, CA, 94547, U.S.A.). ${ }^{3,7,8,13}$

EPH results were obtained from the SPIFE $3000^{\circledR}$ electrophoresis analyzer (Helena Labs, Beaumont, TX, 77707, U.S.A.). ${ }^{5}$ They were subcategorized as abnormal on the basis of at least 105 a 10\%-change (in absolute concentration) compared to the reference intervals of at least one protein fraction.

3-hydroxybutyrate measurement analysis was conducted using the RX Daytona $+{ }^{\circledR}$ instrument with Randox ${ }^{\circledR}$ reagents (Randox Laboratories, Kearneysville, WV, 25430, U.S.A.).

Statistical analysis. Methods validation was conducted according to prior recommendations. ${ }^{15}$

110 Statistical analysis was completed by using XLStat Premium v.18.07 ${ }^{\circledR}$ software (Addinsoft, Paris, France). The $P$-values were obtained by the non-parametric Kruskal-Wallis test used herein for comparing three independent groups of different sample sizes. The guidelines of American Society for Veterinary Clinical Pathology for publication of clinical pathology data were followed. ${ }^{14}$ Reference intervals (RI) were calculated using MedCalc v.16.4.3 (MedCalc

115 software, 8400 Ostend, Belgium) according to parametric double-sided method for normal distribution with $90 \%$ confidence intervals.

\section{RESULTS}


Clinical group definition Characteristics of included penguins are listed in Table 1. Overall, 172 blood samples were collected from naturally-infected cases $\left(n_{l}=47\right)$ and from control penguins with inflammatory disease $\left(n_{2}=29\right.$, inclusive of chronic arthritis, mild viral bronchitis, malaria, chronic anemia, and metastatic adenocarcinoma) or clinically-normal status $\left(n_{3}=96\right.$, as reported by submitting institutions).

Clinical suspicion of aspergillosis was very strong in most diseased cases: $67.6 \%$ showed 125 respiratory signs (e.g. dyspnea, wheezing, gasping, stridor, open-mouth breathing, coughing, changes in vocalizations), $11.8 \%$ neurological signs (e.g. ataxia, opistophonos, torticollis, limb paresis, blindness, behavioural changes), and 76.5\% general signs (e.g. lethargy, anorexia, weight loss, lack of appetite, sternal recumbency, regurgitation).

Antibody and antigen detection. The level of reactivity for anti-Aspergillus antibody was not

130 different between the Aspergillus-diseased cases and the control groups $(P=0.76)$ : $92.3 \%$ $69.2 \%$, and $79.2 \%$, samples expressed positive reactivity with an index $\geq 1.4$ among Aspergillus-diseased, non-Aspergillus inflammatory control and clinically-normal penguins, respectively.

There were also no significant differences between the penguin groups for the mean measure 135 of galactomannan antigen ( $P=0.14$, Table 1$)$. For example, 23.1\% Aspergillus-diseased birds had an antigen an index $\geq 0.7$, whereas $37.5 \%$ non-Aspergillus inflammatory controls had index $\geq 0.7$.

Plasma protein electrophoresis. The albumin/globulin (A/G) ratio, prealbumin concentration, and $\alpha 1$-globulins were found to be significantly lower in the Aspergillus-diseased cases $v s$.

140 clinically-normal penguins $(P<0.005)$. In contrast, $\alpha 2, \beta$, and $\gamma$-globulins were significantly increased in Aspergillus-diseased birds vs. clinically-normal penguins $(P<0.005)$ (Table 1). Notably, respective mean concentrations for the Aspergillus-diseased cases were not different 
from those for the non-Aspergillus inflammatory controls, except for $\alpha 2$-globulins $(1.13 \mathrm{~g} / \mathrm{dL} \pm$ $0.27 v s .0 .86 \mathrm{~g} / \mathrm{dL} \pm 0.20, P<0.05)$. A typical EPH pattern for a clinically normal penguin and a penguin with aspergillosis is shown in Figure 1.

Overall, significant changes were observed for $\mathrm{A} / \mathrm{G}$ ratio in $66.7 \%$ and $58.6 \%$, for prealbumin in $25.6 \%$ and $36.4 \%$, for albumin in $58.5 \%$ and $34.6 \%$, for $\alpha 1$-globulins in $7.3 \%$ and $13.6 \%$, for $\alpha 2$-globulins in $45.2 \%$ and $18.2 \%$, for $\beta$-globulins in $57.1 \%$ and $48.1 \%$, and for $\gamma$ globulins in $36.6 \%$ and $32.1 \%$ of samples from Aspergillus-diseased cases and non-Aspergillus inflammatory controls, respectively. $\beta$-globulins reflected the largest increases in Aspergillusdiseased penguins (+20.4\% compared to upper normal limit). EPH specificity to Aspergillusdisease was determined at $57.3 \%$ [CI 49.4 to 64.6 ] and $74.5 \%$ [CI 66.9 to 80.5 ], when $\geq 1$ and $\geq 2$ protein fraction(s) showed $>10 \%$ significant change from normal ranges, respectively. However, elevated $\alpha 2$-globulins demonstrated high specificity to aspergillosis at $92.2 \%$ [CI 15586.0 to 95.3 ], when positive cutoff was set at $1.0 \mathrm{~g} / \mathrm{dL}$ (but sensitivity was only $45.2 \%$ [CI 33.6 to 57.7]), and the positive (PPV) and negative predictive values (NVP) were at 70.4\% [CI 55.9 to $84.8 \%$ ] and $80.5 \%$ [CI 74.5 to $86.5 \%$ ], respectively.

3-hydroxybutyrate measurement. The mean concentration of 3-hydroxybutyrate in penguin plasma was $1.33 \mathrm{mmol} / \mathrm{L} \pm 0.59$ in Aspergillus-diseased cases (Table 1). It was significantly higher than that observed in the two control groups, i.e. $0.94 \mathrm{mmol} / \mathrm{L} \pm 0.13$ and $0.77 \mathrm{mmol} / \mathrm{L} \pm$ 0.22 for the clinically-normal and the non-Aspergillus inflammatory penguins, respectively $(P=0.002)$ (Figure 2).

Receiving operator characteristic (ROC) curve established the lower positive cutoff at 0.60 $\mathrm{mmol} / \mathrm{L}$, but the specificity was not satisfactory (53.6\%, [CI 35.8 to 70.4$]$ ), in spite of high sensitivity (91.2\%, [CI 77.8 to 95.9]). Thus, the upper positive cutoff was set at $0.94 \mathrm{mmol} / \mathrm{L}$ (sensitivity: 64.7\%, [CI 50.3 to76.0]; specificity: 78.6\%, [CI 71.2 to 84.0]) (Table 2). 
Diagnostic performance of combined tests. With the lower cutoff of 3-hydroxybutyrate $(0.60$ $\mathrm{mmol} / \mathrm{L}$ ) and at least one significant change $>10 \%$ for any protein fraction in EPH, sensitivity and specificity of the combined test were assessed at $64.5 \%$ [CI 49.4 to 76.3 ] and $73.5 \%$ [CI 65.3 to 78.8 ], respectively. The NPV was high, e.g. 86.7\%, [CI 80.1 to 92.9]. When the upper cutoff of $0.94 \mathrm{mmol} / \mathrm{L}$ was used with at least one significant change $>10 \%$ for any protein fraction in $\mathrm{EPH}$, the sensitivity and specificity were at $38.7 \%$ [CI 26.4 to 53.6 ] and $86.9 \%$ [CI 79.7 to 91.2]. The upper 3-hydroxybutyrate cutoff combined with $\alpha 2$-globulins absolute concentration (with positive threshold at $1.0 \mathrm{~g} / \mathrm{dl}$ ), provided excellent overall specificity, i.e. 98.4\% [CI 94.4 to 99.4], while NPV and PPV were both elevated at 79.9\% [CI 72.9 to 85.2] and $77.8 \%$ [CI 55.0 to 1.00$]$, respectively.

\section{DISCUSSION}

As with other animal species and humans, diagnosis of aspergillosis in birds remains difficult. ${ }^{4-6}$ Ante-mortem diagnostics display poor performance. As demonstrated in this study, serological assays are often not able to distinguish between controls and Aspergillus-diseased cases. In the current assay, the mean indices for anti-Aspergillus antibody detection were similar to those observed in 108 other penguins in a prior study. ${ }^{7}$

In contrast to psittacine electrophoretograms where $\beta$-globulins are the dominant globulin

185 fraction in clinically-normal birds, the electrophoretogram of the penguin demonstrates a significant level of protein in the $\alpha 2-$, as well as in $\beta$-globulins, and is a reflection of an increase in a myriad of positive acute phase proteins (Figure 1). ${ }^{4,12,17}$ The significant change in $\alpha 2-$ globulins in Aspergillus-diseased penguins is interesting and may reflect an increase in haptoglobin which may reflect a chronic inflammatory process (C. Cray, personal observation). Changes in $\gamma$-globulins would be consistent with the stimulation of humoral immunity. The $\alpha 1$ - 
fraction remains poorly defined regardless of clinical condition. A prealbumin fraction is present as a shoulder migrating to the left of the albumin fraction. The clinical significance of prealbumin in birds is not been defined; however, prealbumin has been observed to decrease in falcons with naturally-acquired and experimentally-induced aspergillosis. ${ }^{18,26}$ In clinically195 abnormal penguins, a moderate decrease in percent albumin is often present; this is supportive of its designation as a negative acute phase protein. Importantly, EPH has been demonstrated to be the only valid method (vs. bromocresol green methods) for albumin quantitation. ${ }^{6}$

Plasma changes in 3-hydroxybutyrate concentration were hypothesized to have diagnostic relevance upon observation of increased concentration in experimentally-infected falcons. ${ }^{21}$ Its elevation was assumed to reflect the need for energy activating during the infection. ${ }^{1}$

In the current study, it was statistically determined in a cohort of Aspergillus-diseased penguins, with an elevated mean measurement at $1.33 \mathrm{mmol} / \mathrm{L} \pm 0.59$. Notably, a special caution should be raised to the wide confidence interval of the results, suggesting important inter-individual variations, and to the age difference with penguins undergoing non-aspergillosis inflammatory (the potential effects that age could play in the interpretation of results have not been clearly demonstrated). Anyway, in nine penguins with history of resolved Aspergillus-infection (diagnosis established 68 days \pm 14 earlier; $100.0 \%$ recovered when treated with antifungal drugs $)$, the mean concentration for 3-hydroxybutyrate was low $(0.86 \mathrm{mmol} / \mathrm{L} \pm 0.10)$. In contrast, a high value of $6.00 \mathrm{mmol} / \mathrm{L}$ was reported in a severely infected penguin three days prior its death. Overall, concentrations $>1.90 \mathrm{mmol} / \mathrm{L}$ were observed in penguins at the apparent peak of the Aspergillus-disease with significant clinical signs including hyper inflated cervical air sacs, coughing, wheezing and stridor, and strongly suggestive radiographic findings. These findings suggest a possible prognostic value of 3-hydroxybutyrate concentration, as levels return to normal when penguins recover in contrast to very elevated levels when clinical signs of aspergillosis are severe. However, 3-hydroxybutyrate levels have been also studied in finches 
adapting to winter conditions compared to levels measured in the summer: it was found to increase in fasting birds as well as in birds adapted to winter conditions, though stayed relatively static in fed birds in both summer and winter. ${ }^{2}$ This suggests that the variations of 3hydroxybutyrate may be also strongly linked to fasting and overall nutritional status/energy balance. So in order to improve its diagnostic performance, its measurement in blood perhaps requires concomitant additional analysis like comparison in tandem with EPH results. Indeed, combined tests are assumed to be theoretically able to overcome specificity limitations. Because EPH and 3-hydroxybutyrate assessment are two distinct tests, they have independent false-positive and false-negative rates that are unlikely to occur in the same study cases. The results showed that if both EPH fractions and 3-hydroxybutyrate levels were normal, the probability appeared high that the penguin was not infected with Aspergillus with NPV calculated at $86.7 \%$. Furthermore, $\alpha 2$-globulins demonstrated high specificity to aspergillosis at 92.2\%, and it is the reason why its combination with the upper 3-hydroxybutyrate cutoff offered very elevated specificity at $98.4 \%$.

In conclusion, this brief report underscores the potential utility of 3-hydroxybutyrate measurement for the initial diagnosis of aspergillosis in penguins especially when combined with routine testing like EPH. Further studies are warranted in order to confirm the diagnostic and prognostic benefits of 3-hydroxybutyrate in other penguin and avian species. For instance, it may be relevant to compare its measurements in subjects with well-controlled food intake to assert that its increases were not only due to these birds not eating because of severe infection.

Acknowledgements: This project was supported by the African penguin Species Survival Plan (SSP) as part of the Association of Zoos \& Aquariums (AZA) Saving Animals From Extinction (SAFE) conservation initiative. 
240 Thank you to the institutions that enrolled their patients: California Academy of Sciences (San Francisco, CA, U.S.A.), Minnesota Zoo (Apple Valley, MN, U.S.A.), Busch Gardens Tampa (Tampa, FL, U.S.A.), The Maryland Zoo in Baltimore (Baltimore, MD, U.S.A.), Tulsa Zoo\& Living Museum (Tulsa, OK, U.S.A.), Fort Wayne Children's Zoo (Fort Wayne, IN, U.S.A.), Georgia Aquarium (Atlanta, GA, U.S.A.), Sea Research Foundation, Inc. d/b/a Mystic 245 Aquarium (Mystic, CT, U.S.A.), and Cincinnati Zoo and Botanical Garden (Cincinnati, OH, U.S.A.). 


\section{LITERATURE CITED}

1. Albano N, Masero JA, Villegas A, Abad-Gómez JM, Sánchez-Guzmán JM. Plasma metabolite levels predict bird growth rates: a field test of model predictive ability. Comp Biochem Physiol A Mol Integr Physiol. 2011;160(1):9-15.

2. Bech C, Eidsmo Reinertsen R. Physiology of cold adaptation in birds [Internet]. Softcover reprint of the original 1st ed. 1989 (16 avril 2013). Springer-Verlag New York Inc.;

2551989 [cited 2018 Jan 3]. 384 p. Available from://www.springer.com/gp/book/9780306432378

3. Cray C, Arcia G, Schneider R, Kelleher SA, Arheart KL. Evaluation of the usefulness of an ELISA and protein electrophoresis in the diagnosis of Encephalitozoon cuniculi infection in rabbits. Am J Vet Res. 2009;70(4):478-482.

4. Cray C, Reavill D, Romagnano A, Van Sant F, Champagne D, Stevenson R, Rolfe V,

260 Griffin C, Clubb S. Galactomannan assay and plasma protein electrophoresis findings in psittacine birds with aspergillosis. J Avian Med Surg. 2009;23(2):125-135.

5. Cray C, Watson T, Arheart KL. Serosurvey and diagnostic application of antibody titers to Aspergillus in avian species. Avian Dis. 2009;53(4):491-494.

6. Cray C, Watson T, Rodriguez M, Arheart KL. Application of galactomannan analysis and protein electrophoresis in the diagnosis of aspergillosis in avian species. J Zoo Wildl Med. 2009;40(1):64-70.

7. Jones MP, Orosz SE. The diagnosis of aspergillosis in birds. Semin Avian Exot Pet Med. 2000;9(2):52-58. 
8. Robin JP, Boucontet L, Chillet P, Groscolas R. Behavioral changes in fasting emperor penguins: evidence for a "refeeding signal" linked to a metabolic shift. Am J Physiol. 1998;274(3 Pt 2):R746-753.

9. Seyedmousavi S, Guillot J, Arné P, de Hoog GS, Mouton JW, Melchers WJG, Verweij PE. Aspergillus and aspergilloses in wild and domestic animals: a global health concern with parallels to human disease. Med Mycol. 2015;53(8):765-797.

10. Vap LM, Harr KE, Arnold JE, Freeman KP, Getzy K, Lester S, Friedrichs KR, American Society for Veterinary Clinical Pathology (ASVCP). ASVCP quality assurance guidelines: control of preanalytical and analytical factors for hematology for mammalian and nonmammalian species, hemostasis, and crossmatching in veterinary laboratories. Vet Clin Pathol. 2012;41(1):8-17. 


\section{FIGURE LEGENDS}

Figure 1: Typical electrophoretograms of a clinically normal (A) and Aspergillus-diseased African penguin (B). The fractions, from left to right, are prealbumin, albumin, $\alpha 1-, \alpha 2-, \beta-$, and $\gamma$-globulins.

Figure 2: Boxplots showing distribution of 3-hydroxybutyrate measurement in samples collected from Aspergillus-diseased penguins (dark grey, $n=47$ ) and from control penguins undergoing miscellaneous non-Aspergillus inflammatory processes (light grey, $n=29$ ). 